\title{
The impact of the blockchain on the supply chain: a theory-based research framework and a call for action
}

\author{
Horst Treiblmaier \\ Department of International Management, MODUL University Vienna, Vienna, Austria
}

\begin{abstract}
Purpose - This paper aims to strive to close the current research gap pertaining to potential implications of the blockchain for supply chain management (SCM) by presenting a framework built on four established economic theories, namely, principal agent theory (PAT), transaction cost analysis (TCA), resource-based view (RBV) and network theory (NT). These theories can be used to derive research questions that are theory-based as well as relevant for the industry. This paper is intended to initiate and stimulate an academic discussion on the potential impact of the blockchain and introduces a framework for middle-range theorizing together with several research questions.

Design/methodology/approach - This paper builds on previous theories that are frequently used in SCM research and shows how they can be adapted to blockchain-related questions.

Findings - This paper introduces a framework for middle-range theorizing together with several research questions.

Research limitations/implications - The paper presents blockchain-related research questions derived from four frequently used theories, namely, PAT, TCA, RBV and (NT). These questions will guide future research pertaining to structural (PAT, TCA) and managerial issues (RBV, NT) and will foster middle-range theory development in SCM research.

Practical implications - Blockchain technology has the potential to significantly change SCM. Given the huge investments by industry, academic research is needed which investigates potential implications and supports companies. In this paper, various research questions are introduced that illustrate how the implications of blockchain on SCM can be investigated from different perspectives.

Originality/value - To the best of the author's knowledge, no academic papers are published in leading academic journals that investigate the relationship between SCM and blockchain from a theory-based perspective.
\end{abstract}

Keywords Information systems, Business strategy, Disruption, Value chain, Global value chain, Management strategy, Blockchain, Middle-range theorizing

Paper type Research paper

\section{Introduction}

About two decades ago, the internet emerged as an unprecedented and highly disruptive technology that shook the foundations of many established businesses. This upheaval proliferated throughout many supply chains (SCs) and led to the restructuring of complete value networks (Yao et al., 2009; Dresner et al., 2001). While the use of network technology to exchange data electronically (e.g. EDIFACT) had existed long before, it was the widespread adoption of the internet for commerce (both B2B and B2C) that heavily impacted supply chains (Lancioni et al., 2003).

The current blockchain development somewhat resembles those early days of internet adoption, which was slow at first. The roots of the ARPANET, which was an early packet switching network based on TCP/IP, date back to the end of the 1960s. It was not until the commercial potential of the internet was fully realized in the 1990s that the World Wide Web

The current issue and full text archive of this journal is available on Emerald Insight at: www.emeraldinsight.com/1359-8546.htm

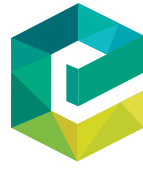

Supply Chain Management: An International Journal 23/6 (2018) 545-559

Emerald Publishing Limited [ISSN 1359-8546] [DOI 10.1108/SCM-01-2018-0029] yielded many user-friendly applications with both positive and negative implications for businesses and individuals (Kambil, 1995). With widespread adoption, the internet had a significant impact on supply chain management by creating electronic marketplaces, helping to realize cost reductions, increasing productivity, enabling e-procurement, integrating business processes and allowing for the creation of customized services (Lancioni et al., 2003). It is now the blockchain which offers similar promises, and a rigorous academic investigation is needed into the extent to which it may help businesses to create value.

The general pattern of interest in the blockchain exhibits several years of slow adoption followed by exponential growth starting at the end of 2015 and a spike of the end of 2017, which was caused by massive public interest in Bitcoin (Google Trends, 2018). Similar to the internet, the blockchain is not a

\footnotetext{
(C) Horst Treiblmaier. Published by Emerald Publishing Limited. This article is published under the Creative Commons Attribution (CC BY 4.0) licence. Anyone may reproduce, distribute, translate and create derivative works of this article (for both commercial and non-commercial purposes), subject to full attribution to the original publication and authors. The full terms of this licence may be seen at http://creativecommons.org/licences/by/4.0/legalcode
}

Received 23 January 2018

Revised 1 August 2018

Accepted 7 August 2018 
single technology but rather operates on a stack of technologies that includes the internet as an infrastructure and uses the blockchain protocol for storing transaction records and establishing consensus rules. Various applications such as smart contracts can be operated on the application layer, yet the full range of potential applications is still unclear (World Economic Forum, 2017). Proponents of the blockchain point out that it enables the creation of a so-called "Internet of Value" (Deloitte, 2016), through which property rights can be transferred online. This marks a key development from the "Internet of Information", in which users can share information but cannot be prevented from creating infinitely many copies.

The ongoing discussions regarding the potential impact of the blockchain and lack of research on this topic notwithstanding, many companies are investing huge sums of money in blockchainbased solutions that bear the potential to revolutionize SCs. According to Juniper Research, which conducted a study amongst 369 company founders, executives, managers and IT experts, 76 per cent of respondents believe that the blockchain could be "very useful" or "quite useful" for their company, 35 per cent expect significant internal disruptions and 51 per cent anticipate significant disruptions to their partners or customers (Holden and Moar, 2017). An IBM study reports that one-third of organizations are considering or actively engaged with blockchain technology, with numbers varying by industry. Using input from 2,965 C-suite executives the IBM study reports that early adopters ("explorers") are experiencing disruptions in their industry twice as often as so-called "passives" (60 vs 30 per cent) and that explorers are much more likely to disrupt a market or industry themselves by "changing the rules of the game" (21 vs 5 per cent) (IBM, 2017, p. 7). The whole blockchain market size is estimated to grow from US $\$ 210.2 \mathrm{~m}$ in 2016 to US $\$ 2,312.5 \mathrm{~m}$ by 2021 , at a compound annual growth rate of 61.5 per cent (Markets and Markets, 2016).

The academic relevance of the blockchain has already been acknowledged for supply chain management (SCM) and logistics (Kshetri, 2018). Furthermore, a substantial number of publications in academic conferences and white papers are already being published which critically investigate the blockchain (Romano and Schmid, 2017) and its potential applications in the field of SCM/logistics (Hackius and Petersen, 2017; Oakley, 2017). For academic research to be able to make impactful contributions that benefit the industry, it is crucial that researchers apply their core competence of rigorous research methodology to scrutinize blockchain and its potential implications on SCM.

The aim of this paper is threefold. First, following the suggestion from MacInnis (2011) that conceptual contributions necessitate the identification, delineation and differentiation of the particular entity or a domain, this paper seeks to clearly define and delimit the domain occupied by the blockchain.

Second, to demonstrate the applicability of the blockchain within the field of SCM/logistics, the basic functionality of the blockchain is explained to provide some indication of the blockchain's potential future impact on supply chains.

Third, the major goal of this paper is the development of a theoretical framework for further research that allows the derivation of research questions which are based on theory and enable methodologically rigorous research designs. The framework we elaborate is based on four widely used general theories - principal agent theory (PAT), transaction cost analysis (TCA), also called transaction cost theory, resourcebased view (RBV) and network theory (NT) (Halldórsson et al., 2007) - which can be applied to explore the implications of the blockchain. The combination of these four theories allows for the simultaneous consideration of structural as well as managerial aspects from the perspective of new institutional economics. This framework, which is made up of research questions pertaining to the respective theories, allows for the further creation of middle-range theories and propositions that can later be empirically tested and provides an initial understanding of the "inner workings within key relationships" (Stank et al., 2017, p. 6). It will therefore enable researchers to systematically investigate the blockchain phenomenon and its potential implications from varying theoretical standpoints. More specifically, it will help to answer two overarching research questions:

RQ1. How to structure a supply chain that incorporates the blockchain?

RQ2. How to manage a supply chain that incorporates the blockchain?

Questions regarding how to structure a supply chain (SC) are primarily addressed using PAT and TCA, while questions about what is needed for managing such structures fall under the domain of RBV and NT. This paper ends with a brief discussion of theoretical and managerial implications and suggestions for future research.

\section{The blockchain: functioning, definition and impact assessment}

The basic unit of a blockchain is a single transaction that involves one or more entities. This could be a payment process but might as well be a transfer of information. A cryptographic hash function, which takes an input and returns an alphanumeric string of fixed length, is used to create so-called transaction hashes that encode the contents of this transaction. These transaction hashes cannot be used to recreate the original transaction and are visible in case the blockchain is public. Several transactions are subsequently combined into one single block, which in most cases is verified by so-called miners who deploy computing resources that compete amongst each other to create the next block. If a block is successfully validated, it is appended to the chain of previous blocks, hence the term blockchain. A new block is connected with previous blocks in a way that makes it increasingly hard to remove from the total chain.

The whole process of validating transactions and adding blocks in a public blockchain is fully distributed such that no single controlling authority exists (Nakamoto, 2008; Raval, 2016). Sophisticated procedures exist to circumvent fraud (e.g. double spending) which is why it is sometimes written that the blockchain leads to trustless consensus. An important characteristic of blockchains is their resistance to the modification of data. Transactions on the blockchain cannot be later modified or removed because of the linking of the blocks together. The longer the chain, the harder it is to make modifications in previous blocks, and thus the higher the level of trust (Narayanan et al., 2016). 
We thus define the blockchain as a digital, decentralized and distributed ledger in which transactions are logged and added in chronological order with the goal of creating permanent and tamperproof records.

Decentralization refers to a situation whereby no single entity controls transaction processing, while distribution relates to the computational work that is divided between several computers. Distributed Ledger Technology (DLT) is a broad term which describes all technologies that distribute information across multiple sites, countries or institutions and which includes the blockchain. If a dedicated group of owners or users exists, the ledger is permissioned and private (e.g. a clearing or settlement network). If the usage is public, but the integrity is maintained by trusted ledger owners, it is called a permissioned, public shared ledger (e.g. a global financial transaction system). Finally, if the integrity is ensured by the users themselves through untrusted consensus, this is called an unpermissioned public shared ledger (e.g. a cryptocurrency such as Bitcoin) (UK Government, 2016).

\subsection{Industry adoption of the blockchain}

It was Bitcoin, a cryptocurrency application of the blockchain, which first drew public attention to this technology. In 2008, a seminal paper entitled "Bitcoin: A Peer-to-Peer Electronic Cash System" was published under the name of Satoshi Nakamoto, (Nakamoto, 2008), and in January 2009, the first open source Bitcoin client was released with Nakamoto, himself being the first miner. This name was later revealed to be a pseudonym and the actual inventor (or group of inventors) of Bitcoin still remains unknown. In the years to follow, it was the computer science and cryptography communities that were most occupied with the technology, but attention broadened around 2010/2011 when Bitcoin started to take off with exponential trade volumes and a dramatic price increase (Alabi, 2017).

Bitcoin has paved the way for a multitude of so-called Altcoins to follow, many of which were actually derived ("forked") from the original Bitcoin implementation. Those Altcoins serve different purposes ranging from replacing fiat money to more specific applications such as supplanting the use of the USA dollars in the container shipping industry with tokens launched by open-source blockchain-based platforms (MarEx, 2017). Current use cases go far beyond simply using the blockchain as a technological platform for currencies and have now started to include the implementation of so-called smart contracts, for example, on the Ethereum platform. This was made possible by an extension of the basic functionality of the blockchain that enabled the implementation of complex business logic. Smart contracts are agreements between two or more contracting parties which can be automatically enforced without any intermediaries. These agreements exist in the form of software code on the blockchain platform, which ensures their autonomy and self-executive nature based on predefined rules (Savelyev, 2017). The blockchain is frequently labeled a "disruptive" technology, but, as Iansiti and Lakhani (2017) point out, it would be more appropriate to call it a foundational technology, as it can create new foundations for social and economic systems.

Although at present the full range of potential blockchain applications is still unclear, many use cases have been suggested for various kinds of industries. A notable example in manufacturing, SCM and logistics involves combining the internet of things (IoT) and the blockchain. This combination has the potential, for example, to enable connected vehicles that automatically communicate their current status and smart locks that give access to real-world objects. Blockchain platforms can also be used for SC tracking applications which keep a formal product registry and are able to track possession of goods at different stages in the chain. Other ideas include smart diagnostics, which will enable machines to monitor their state and diagnose problems and smart contracts between manufacturers and vendors for the procurement of supplies and service of machinery (Bahga and Madisetti, 2016). Additionally, it would be possible to track the identity and reputation of suppliers and to use smart contracts to automatically negotiate best prices in real time while taking into account the seller's reputation (Bahga and Madisetti, 2017). On a more general level, Field (2017) predicts that the blockchain will lead to improved SC visibility, SC optimization and better demand forecasting, as increased transparency will make it possible to react in real time to unforeseen events. This will also have a positive effect on inventory management. The general expectation is that the blockchain will help to reduce fraud and errors, reduce transit and shipping costs as well as waste and improve inventory management (JOC, 2017).

\section{Research methodology}

The two main goals of this paper are the systematic and theorybased identification of structural and managerial changes that are triggered by the introduction of the blockchain into SCs. To address those issues, we first needed to identify theories that have proven useful in raising questions related to structural and managerial aspects, followed by a systematic way to generate research questions. We identify the theories suggested by Halldórsson et al. (2007) as the most suitable for the aforementioned research goals, as they not only combine structural and managerial issues in a single comprehensive framework but also have been previously validated in various replication studies (Halldórsson et al., 2015). The theoretical framework proposed here was generated by applying the various characteristics of the respective theories to blockchainbased SCM scenarios. The exemplary research questions presented were generated by applying the main goals of four different theory types to the characteristics of the respective theories. To ensure the validity of our study, the resulting frameworks were independently evaluated by three other researchers and modifications were made to the wordings until all researchers agreed upon the validity of the findings (Grayson and Rust, 2001).

\section{Theorization of blockchain-induced SCM}

Previous research has suggested that the logistics discipline can benefit from borrowing theories from other areas (Stock, 1997). This paper builds upon the theoretical framework initially suggested by Halldórsson et al. (2007) which compares and combines four popular theories that are widely used in social science and economic research. They provide an institutional as well as socio-economic perspective to answer questions of how to structure and manage a particular SC. 
Subsequent studies have shown that these theories and adaptations thereof have been successfully applied in a wide variety of contexts in SCM research (Defee et al., 2010; Kembro et al., 2014; Halldórsson et al., 2015; Swanson et al., 2017). They have been used to successfully describe, explain and predict changes in SCM that are caused by disruptive technologies.

In the following sections the four theories and their importance for SCM research are briefly explained, followed by the integration of the blockchain and a framework for the development of blockchain-based middle-range theories as well as specific research questions.

\subsection{Complementary theories in SCM/logistics management}

Agency costs within PAT can be defined as the sum of monitoring expenses by the principal, bonding expenditures by the agent and residual loss (Jensen and Meckling, 1976). They occur as the principal wants to monitor, supervise and control the agent, so that the latter acts in the best interest of the former. The principal has incomplete information regarding the agent's behavior and therefore has to trust the agent to a certain extent. Fayezi et al. (2012) identified 86 SCM-related articles dealing with agency theory and principal-agent relationships, 19 of which they closely investigated. Simply put, the major challenge for the principal lies in selecting the right agent and building a relationship based on trust. Previous principal-agent studies related to SCM have focused on issues as diverse as the impact of Sarbanes-Oxley on off-balance sheet SC activities (Kros and Nadler, 2010), performance improvements (Miller et al., 2013), demand uncertainty and price competition (Narayanan et al., 2005), SC quality management ( $\mathrm{Zu}$ and Kaynak, 2012), the likelihood of quality fade in buyer-supplier relationships (Whipple and Roh, 2010) and the reduction of supply risk (Zsidisin and Ellram, 2003).

TCA postulates that the selection of the most efficient types of inter- and intra-organizational structures impacts the efficiency of different types of governance mechanisms in terms of production and transaction costs (Coase, 1937). Transaction costs include ex ante costs of initiation (search and information) and agreement (negotiation and decisionmaking) and ex post costs of control and adjustment. Depending on the costs of market transactions, different governance structures, such as markets or hierarchies, might emerge (Williamson, 1987; Picot et al., 1997; Strebinger and Treiblmaier, 2006). TCA provides a rich theoretical base for SCM, and measurement tools, guidelines and research propositions have been developed to investigate topics such as outsourcing vs purchase decisions, allocation of investments and SC coordination, integration and distribution (Grover and Malhotra, 2003). Exemplary cases in SCM include the application of TCA in the context of information sharing (Yigitbasioglu, 2010), suppliers' adoption of environmental practices (Tate et al., 2011), purchasing portfolio management (Luzzini et al., 2012), performance effectiveness of relational and contractual governance (Wacker et al., 2016) and the perception of transaction risks (Stranieri et al., 2017).

The RBV emerged as a countermovement to the positioning school, which emphasized the importance of strategy for a particular organization (Porter, 1980). In contrast, the RBV postulates that it is only a subset of a company's resources that creates competitive advantage and an even smaller subset which leads to superior performance in the long term. The possession of scarce resources leads to the creation of competitive advantage which can be sustained for as long as the company can protect its resources and no substitutes emerge (Wernerfelt, 1984; Barney, 1991). Halldórsson et al. (2007, p. 288) stated that "only a few articles have applied the resource-based view (RBV) to the field", but a growing number of studies have highlighted the usefulness of this theory and closely related concepts such as the resource-advantage theory (Hunt and Davis, 2008) for SCM research. Amongst others, more recent SCM articles have investigated the impact of companies' resources and capabilities on logistics performance (Yang and Lirn, 2017), the role of market information in creating an informational advantage for transportation providers (Golicic et al., 2012), interorganizational learning (Manuj et al., 2013), achievement of closed-loop SC designs (Miemczyk et al., 2016) as well as the determination of SC information integration antecedents (Huo et al., 2016).

NT seeks an understanding of the dynamics of interorganizational relations by focusing on personal relationships between the parties as well as the mutual creation of trust through cooperative relations and exchange processes (Halldórsson et al., 2007). To gain access to external resources, companies have to establish relationships. On a larger scale, this creates networks that are both stable and changing. Two interaction types, exchange processes (social, business and informational) and adaption processes (products, production and routines), help to establish stable links within a network of firms (Johanson and Mattsson, 1987). Important aspects of NT have been incorporated in a wide variety of SCM topics, including, for example, manufacturing joint venture formations (Carnovale and Yeniyurt, 2014), network centrality antecedents in an environmental SCM initiative (Wichmann et al., 2015), the functioning of strategic networks and alliances (Klint and Sjöberg, 2003) and networked versus nonnetworked companies in the software industry (Kulmala and Uusi-Rauva, 2005).

Table I contrasts the major characteristics of the four theories. All of them assume a certain level of bounded rationality but take a different problem orientation when it comes to investigating the underlying object of interest. PAT is mostly focused on how to design optimal contracts to avoid problems of asymmetric information. TCA explores the borders of organizations resulting in an optimal organizational size and efficient governance structures. RBV focuses on differences between companies and investigates the internal competences that help companies to gain a competitive advantage and, finally, NT deals with dyadic relationships and the networks in which they are imbedded (Halldórsson et al., 2015). Accordingly, Table I also lists the key questions one needs to ask when applying the respective theory, the primary focus of analysis, the nature of relations and the primary domain of interest. All four theories thus take a different stance when it comes to explaining and exploring real-world SCM phenomena; combining them for methodological plurality allows for a more comprehensive investigation of a multifaceted research topic than would be possible with a single theory (Georgi et al., 2010). 
Table I Comparison of the PAT, TCA, the RBV and the network perspective

\begin{tabular}{|c|c|c|c|c|}
\hline Characteristics & PAT & TCA & RBV & NT \\
\hline Behavioral assumptions & $\begin{array}{l}\text { Bounded rationality, } \\
\text { asymmetric information, goal } \\
\text { conflicts }\end{array}$ & $\begin{array}{l}\text { Bounded rationality, } \\
\text { opportunism }\end{array}$ & Bounded rationality, trust & Bounded rationality, trust \\
\hline Problem orientation & Contract design & $\begin{array}{l}\text { Efficient governance } \\
\text { structure }\end{array}$ & $\begin{array}{l}\text { Internal competence } \\
\text { development }\end{array}$ & $\begin{array}{l}\text { Dyadic relationships embedded in } \\
\text { networks }\end{array}$ \\
\hline Key questions & $\begin{array}{l}\text { What is the most efficient } \\
\text { contract? }\end{array}$ & Why do firms exist? & Why do firms differ? & How do networks evolve? \\
\hline Primary focus of analysis & Contracts and incentives & Transaction attributes & Resource attributes & Inter-firm relations \\
\hline Nature of relations & $\begin{array}{l}\text { Division of labor, ownership, } \\
\text { control }\end{array}$ & Market failures & $\begin{array}{l}\text { Access to complementary } \\
\text { resources }\end{array}$ & Access to heterogeneous resources \\
\hline Primary domain of interest & Incentive alignment in dyads & Transactions & $\begin{array}{l}\text { Organizational resources and } \\
\text { capabilities }\end{array}$ & $\begin{array}{l}\text { Exchange and adaptation } \\
\text { processes }\end{array}$ \\
\hline
\end{tabular}

Source: Adapted from Halldórsson et al., 2015, p. 578; Halldórsson et al., 2007, p. 289; Skjoett-Larsen, 1999, p. 46; Madhok, 2002, p. 540

\subsection{A framework for blockchain research in SCM/ logistics}

Analyzing the potential implications of the blockchain from different theoretical angles provides promising starting points for further theory development and empirical research. The main characteristics of the blockchain include decentralization of decision making, distributed processing, reliability, peer-topeer transmission, immutability of data, automaticity, speed, low transaction fees, transparency with pseudonymity and nonrepudiability (irreversibility) (Nakamoto, 2008; Narayanan et al., 2016; Bahga and Madisetti, 2017; Iansiti and Lakhani, 2017). These characteristics lead to derived concepts on a higher level which bear substantial managerial implications such as provenance of data, trust, privacy, security, enforcement, integrity, consensus, availability, authenticity and accountability (Tapscott and Tapscott, 2016; Tschorsch and Scheuermann, 2016; Liang et al., 2017; Neisse et al., 2017) all of which might have severe implications for the SCM/logistics field (Field, 2017; Hackius and Petersen, 2017; JOC, 2017; MarEx, 2017).

Table II shows how these attributes of the blockchain can be integrated into the four theories by adapting the framework from Table I. The structure of this table (i.e. the respective categories) was taken from Halldórsson et al. (2007) who applied this framework to third party logistics. The topics shown in Table II were gained by applying the characteristics of the four theories, as shown in Table I, to blockchain technology. This process was done by the authors of this paper based on the existing literature and on independent feedback from three additional researchers. The characteristics of the four theories were sent via e-mail together with an invitation to propose the most important topics. After the initial round the results were sent to all researchers for final confirmation.

The most important findings were that, from a PAT perspective, smart contracts have the potential to solve or alleviate the problem of information asymmetry (ISDA, 2017). TCA can help to explain how the costs of intra- and interorganizational transactions will change through the blockchain and to what extent this will impact organizational borders (Cocco et al., 2017). RBV can help with the allocation of resources to gain competitive advantage. The specific characteristics of the blockchain are expected to render certain advantages obsolete but might also provide strategic

Table II The Theoretical framework applied to blockchain-based SCM research

\begin{tabular}{|c|c|c|c|c|}
\hline Characteristics & PAT & TCA & RBV & NT \\
\hline Behavioral assumptions & $\begin{array}{l}\text { Increased information } \\
\text { transparency }\end{array}$ & $\begin{array}{l}\text { Contractual agreements } \\
\text { Investments, divestments }\end{array}$ & $\begin{array}{l}\text { Trust in transactions, } \\
\text { knowledge transfer }\end{array}$ & $\begin{array}{l}\text { Interorganizational trust, } \\
\text { information sharing }\end{array}$ \\
\hline Problem orientation & $\begin{array}{l}\text { Contract design and } \\
\text { execution, supervision }\end{array}$ & Outsourcing and insourcing & $\begin{array}{l}\text { Resource allocation and } \\
\text { development }\end{array}$ & $\begin{array}{l}\text { Design of communication and } \\
\text { transactions }\end{array}$ \\
\hline Key questions & $\begin{array}{l}\text { How does the blockchain } \\
\text { impact contract efficiency? }\end{array}$ & $\begin{array}{l}\text { How does the blockchain } \\
\text { change transaction costs? }\end{array}$ & $\begin{array}{l}\text { What blockchain-related } \\
\text { resources generate } \\
\text { competitive advantage? }\end{array}$ & $\begin{array}{l}\text { To what extent does the } \\
\text { blockchain replace personal } \\
\text { trust? }\end{array}$ \\
\hline Primary focus of analysis & $\begin{array}{l}\text { Smart Contracts to control } \\
\text { agent }\end{array}$ & $\begin{array}{l}\text { Costs of intra- and inter- } \\
\text { organizational transactions }\end{array}$ & $\begin{array}{l}\text { Competitive consequences of } \\
\text { resource reallocation }\end{array}$ & Relationships in the network \\
\hline Nature of relations & $\begin{array}{l}\text { Harmonizing conflicting } \\
\text { goals }\end{array}$ & $\begin{array}{l}\text { Arm's length relationships vs } \\
\text { strategic relationships }\end{array}$ & $\begin{array}{l}\text { Blockchain as a new } \\
\text { competence, complementary } \\
\text { resources }\end{array}$ & $\begin{array}{l}\text { Contractual relations, personal } \\
\text { relations }\end{array}$ \\
\hline Primary domain of interest & $\begin{array}{l}\text { Alignment of conflicting } \\
\text { interests with smart contracts }\end{array}$ & $\begin{array}{l}\text { Optimization of transaction } \\
\text { costs, asset specificity, } \\
\text { change of costs }\end{array}$ & $\begin{array}{l}\text { Identification and } \\
\text { development of core } \\
\text { competencies }\end{array}$ & $\begin{array}{l}\text { Mutual adaptation of relations } \\
\text { through blockchain } \\
\text { technology }\end{array}$ \\
\hline
\end{tabular}


opportunities for fast adopters (IBM, 2017). Finally, the blockchain's promise to create "trustless trust" (Werbach, 2018) can be systematically analyzed by applying NT.

As the logistics field has evolved from a rather descriptionbased discipline to one that is founded upon solid theoretical grounding, a need for middle-range theorizing has arisen (Stank et al., 2017; Craighead et al., 2016). As opposed to general theorizing, middle-range theories are more specific regarding the field, of analysis and focus on a better understanding of why, how and when specific outcomes occur (Astbury and Leeuw, 2010). A complementary taxonomy of theories classifies them according to their methodological approach, which can be analysis, explanation, prediction, explanation plus prediction or prescription (Gregor, 2006). While analysis is mainly a descriptive approach focusing on "What?" questions, explanation answers "Why?", "How?", "When?" and "Where?" questions. Theories focusing on prediction create testable propositions but may lack justifiable causal explanations, while design and action research gives prescriptions for constructing artifacts (Gregor, 2006).

Table III lists the different methodological starting points and the respective research objects together with those key questions that can be used to derive testable and theory-based propositions, hypotheses and models. To better understand the potential implications of the blockchain on the respective research objects, it is useful to thoroughly analyze changes in relations between principals and agents, organizational boundaries, critical resources and relationship structures. In contrast, a predictive research design will focus on the changes that are to be expected and a design and action approach makes prescriptions on how to deploy blockchain applications to achieve desired results. As far as middle-range theories are concerned, explanatory questions are of the greatest significance, as they focus on the underlying rationale of why, how and under which conditions certain phenomena occur. Applying these three core explanatory questions to the respective research objects within a SCM/logistics context will help to create middle-range theories that are based on substantiated previous research but at the same time are specific enough to provide insights that are relevant for the logistics industry.

Formulating middle-range theories starts with accumulated knowledge about a phenomenon within a particular domain. This knowledge may stem not only from previous theory-based frameworks but also from inductive, qualitative observations of practice (Stank et al., 2017; Kim et al., 2009). Combining the respective research objects and the key questions listed in Table III enables the deduction of research questions that are directly related to the implications of the blockchain on the SC. In the following paragraphs, we will briefly describe and visualize the expected changes from the points of view of the four theories, respectively, and present exemplary research questions that are of importance for SCM/logistics research.

The central feature of the PAT is the complex relationship between principal and agent, which is characterized by the asymmetric information flows depicted in the left part of Figure 1. It is only the agent who receives information from various external sources (e.g. customers, suppliers and partners), processes this information and acts upon it. As a consequence, the principal has to trust the hired agent and can only assess their general performance but lacks knowledge about details. Under the assumption that the agent will naturally act according to self-interest, the principal has to trust that the agent will pursue the principal's interests, which may require the establishment of trust mechanisms and control systems at additional cost (Jensen and Meckling, 1976). In a blockchain-based scenario (right part of Figure 1), however, information flows are transparent and accessible to both the principal and the agent. As a consequence, the demand for trust vanishes. Blockchain technology thus provides formal guarantees to both parties that comprehensively address agency problems (Kaal, 2017).

Table IV lists some central research questions that arise from applying the questions in Table III to situations in which the blockchain is introduced, as predicted by scholarly as well as practitioner literature. All of the respective questions can be embedded into the general setting of PAT but provide enough specificity to constitute a middle-range theory that leads to useful outcomes for SCM research. All explanatory questions starting with "Why" shown in the following tables are based on the assumption that an effect exists, which must first be confirmed in a preliminary study.

TCA focuses on transactions costs that determine the size and structure of organizations. The immutability of blockchain records in combination with cryptographic security creates new forms of trust that are based on transparency and traceability. The rules that are embedded in blockchain code cannot be circumvented without detection (Kaal, 2017). In the case of smart contracts, the rules are enforced automatically without any need for human intervention.

Table III A framework for blockchain-based middle-range theory development

\begin{tabular}{|c|c|c|c|c|}
\hline Characteristics & PAT & TCA & RBV & NT \\
\hline Research object & Relation between principal and agent & $\begin{array}{l}\text { Organization } \\
\text { Boundaries }\end{array}$ & Critical resources & Relationship structures \\
\hline Analysis & \multicolumn{4}{|c|}{ What are the implications of the blockchain for ...? } \\
\hline Explanation & $\begin{array}{l}\text { Why does the blockchain change ...? } \\
\text { How does the blockchain change ...? } \\
\text { Under which conditions (When?) does }\end{array}$ & kchain change & & \\
\hline $\begin{array}{l}\text { Prediction } \\
\text { Design and } \\
\text { action }\end{array}$ & \multicolumn{4}{|c|}{ If specific changes in ... are desirable, the blockchain can be deployed in the following way: ... } \\
\hline
\end{tabular}


Figure 1 Traditional PAT (left) and blockchain-induced transformations (right)

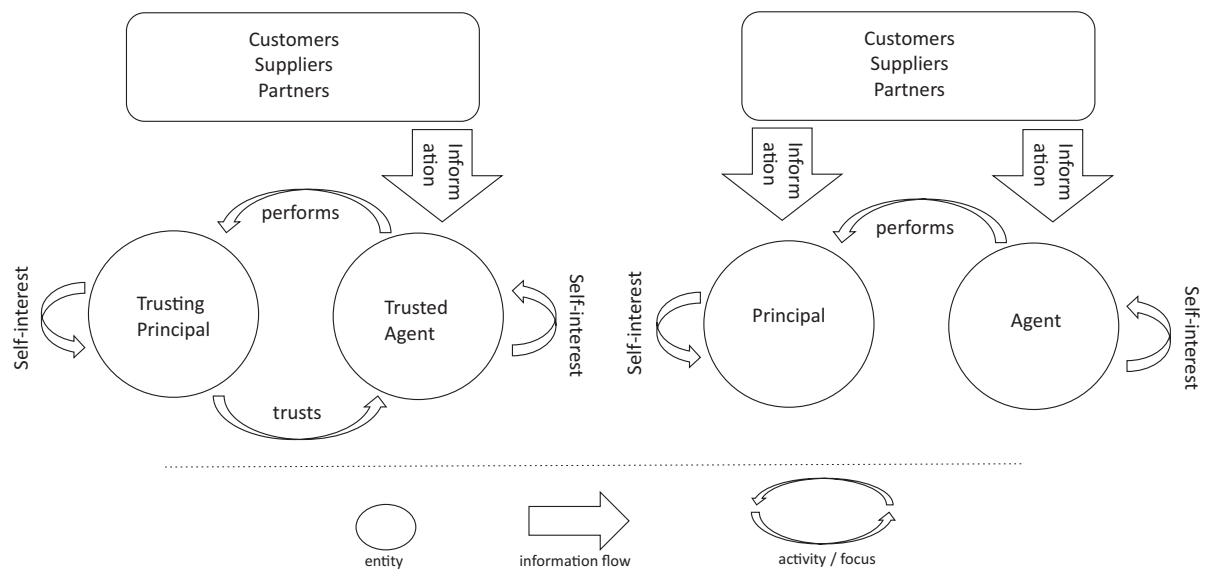

Table IV PAT and blockchain: exemplary research questions

\begin{tabular}{|c|c|}
\hline Theory type & Question \\
\hline Analysis & $\begin{array}{l}\text { What are the implications of specific blockchain characteristics (e.g. increased transparency, immutability, persistence of information) for } \\
\text { the relationship between principal and agent? }\end{array}$ \\
\hline \multirow[t]{4}{*}{ Explanation } & $\begin{array}{l}\text { Why does the blockchain change the relationship between principal and agent? (i.e. which characteristics of the blockchain are responsible } \\
\text { for this transformation?) }\end{array}$ \\
\hline & $\begin{array}{l}\text { How does the relationship between principal and agent change because of the increased transparency (immutability, persistence) of } \\
\text { information? }\end{array}$ \\
\hline & Under which external circumstances (e.g. types of industry, competitiveness of environment) does the blockchain lead to disruptions? \\
\hline & Which types of industries are especially affected? \\
\hline Prediction & $\begin{array}{l}\text { Will the blockchain reduce the level of trust needed in business relationships and lead to an increased number of loose supplier } \\
\text { relationships? }\end{array}$ \\
\hline $\begin{array}{l}\text { Design and } \\
\text { Action }\end{array}$ & How can one create blockchain solutions that help to reduce the level of trust needed and to increase information transparency? \\
\hline
\end{tabular}

Figure 2 shows different types of transaction costs and how they can be affected by the blockchain. Transaction costs can be internal (only shown for company A in Figure 2), representing bureaucratic costs that occur inside a company or external and relating to exchanges between companies. On the left side of Figure 2 company A conducts business with two other companies, B and C. The adoption of blockchain technology potentially affects internal and external transaction costs simultaneously and thus can lead to the shrinking or expansion of a company's boundaries (indicated by the dotted boundaries and the arrows on the right side of Figure 2). Additionally, from the point of view of company A, it might no longer be necessary to continue business relations with companies whose services can be substituted by the blockchain (i.e. company C). This is predicted, for example, for services as diverse as clearing, trade settlement and regulatory reporting (Harwood-Jones, 2016). On the other hand, new market players offering services needed for blockchain technology might emerge (company D). In a nutshell, all internal and external transaction costs may be affected in nature and size. To avoid clutter, disintermediation is not shown in Figure 2, but it can easily be conceived that services from companies which currently benefit from being information and service hubs might become obsolete. In the transportation and logistics field this includes various services related to the validation of transactions.

Table $\mathrm{V}$ shows research questions that arise when TCA and blockchain are combined with the goal of creating middlerange theories.

By applying RBV those resources can be identified and analyzed that help a company to gain and sustain competitive advantage. Figure 3 differentiates between resources in general, capabilities that distinguish a company and finally, those resources which enable competitive advantage on the market. blockchain technology might lead to transformation processes that affect all three levels simultaneously, as is indicated by the dotted lines (right part of Figure 3). This can either be an increase or a decrease of the respective resource, capability or competitive advantage. Smart contracts, for example, have the potential to automate processes by running rules encoded in computer programs. Agents can be hired by so-called decentralized autonomous organizations (DAO), which are run by smart contracts, to perform specialized tasks (Morabito, 2017).

As is shown by the dotted lines representing new boundaries in Figure 3, such a scenario can lead to a reduction of unique competencies for those companies that 
Figure 2 Traditional TCA (left) and blockchain-induced transformations (right)

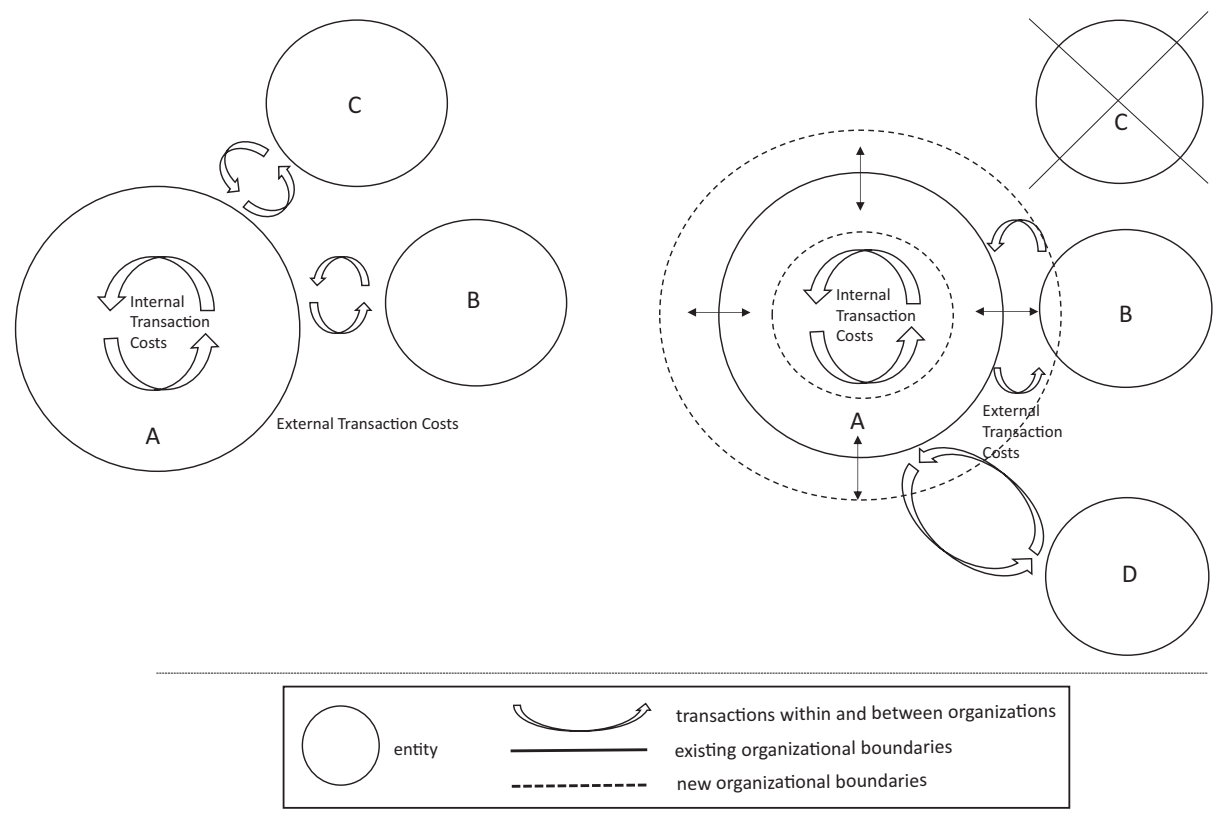

Table V TCA and blockchain: exemplary research questions

\begin{tabular}{ll}
\hline Theory type & Question \\
\hline Analysis & $\begin{array}{l}\text { What are the implications of changes in transaction costs because of the Blockchain on organizational size, structure, interorganizational } \\
\text { transactions and SCs? } \\
\text { Explanation }\end{array}$ \\
& $\begin{array}{l}\text { Why do organizational boundaries change because of the blockchain? (i.e. which blockchain characteristics lead to changes in transaction } \\
\text { costs? } \\
\text { How do contractual agreements between organizations change because of the blockchain? } \\
\text { Which conditions foster or impede blockchain-induced changes? (e.g. type of industry, dependence on contractual agreements, resources } \\
\text { necessary to enforce contractual agreements) } \\
\text { Will the blockchain reduce different types of transactions costs (e.g. costs for search, information, negotiation, decision-making, control, } \\
\text { adjustment) and reshape SCs? } \\
\text { Action }\end{array}$
\end{tabular}

offer services which can be potentially substituted by the blockchain, but it can also lead to an increase in competencies for those companies that can use the new technology to complement their own portfolio of services being offered. On the lowest level, attributes of the blockchain such as data transparency and non-repudiability offer opportunities for cost reduction and independence from the services of intermediaries. On the highest level, new business models may emerge and existing companies might find innovative ways to incorporate blockchain technology into their portfolio of services. The blockchain has been claimed to hold the potential to "disrupt the disruptors" and companies such as Uber and Airbnb, which build their competitive advantage on centralized databases and control structures, might no longer be able to sustain their existing business models (Ogundeji, 2016). Similar to the internet, blockchain technology thus bears the potential to fundamentally alter the importance of (critical) resources for sustained advantage across industries independent of factors such as company size or managerial experience.

Table VI presents several research questions that investigate the impact of the blockchain from an RBV perspective and which can serve as guidelines for middlerange theory building.

NT investigates the nature and role of interorganizational relationships and how they can be managed. NT is similar to TCA in that it investigates connections between organizations but focuses on the management of relations rather than transactions (Rinehart et al., 2004). On the left side of Figure 4 two types of relationships are shown: a direct one between $\mathrm{A}$ and $\mathrm{B}$ and an indirect (mediated) one between $\mathrm{A}$ and D. On the right side, the potential impact of the blockchain is shown. The relationship between companies A and B still exists, but its nature and strength might have changed. Additionally, the previously indirect relationship between $\mathrm{A}$ and $\mathrm{D}$ was substituted by a direct one and the intermediary $\mathrm{C}$ was 
Figure 3 Traditional RBV (left) and blockchain-induced transformations (right)

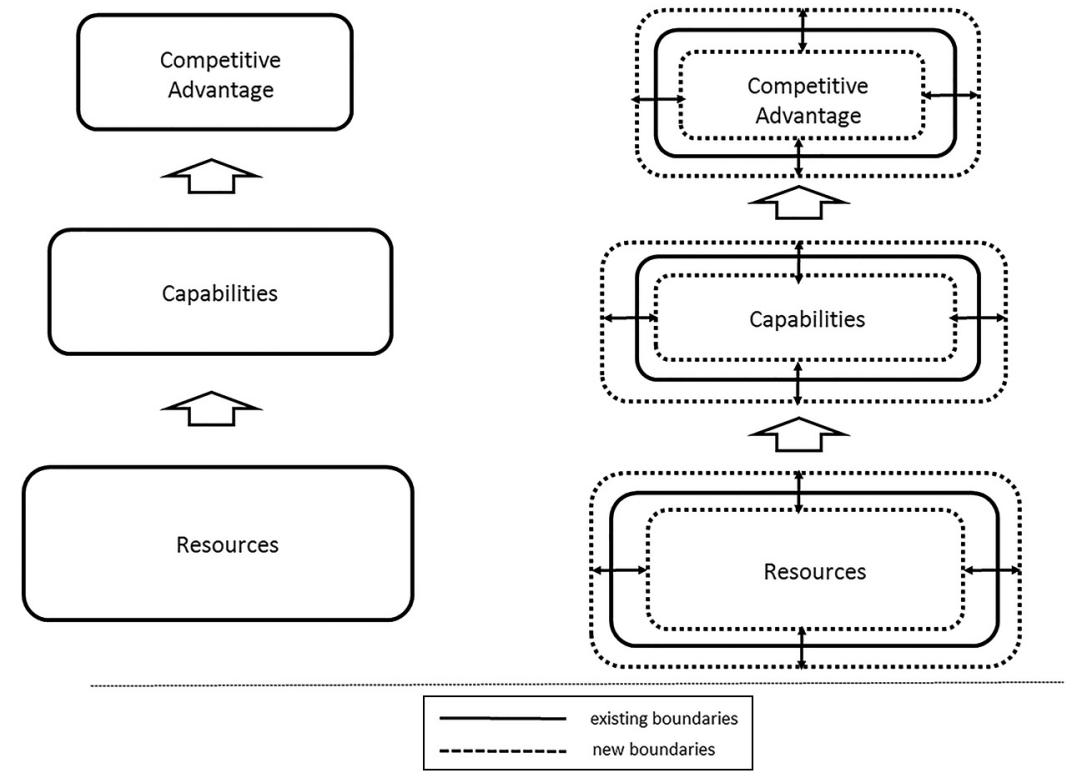

Table VI RBV and blockchain: exemplary research questions

\begin{tabular}{|c|c|}
\hline Theory type & Question \\
\hline Analysis & What are the implications of the blockchain for internal resources and competitive advantage? \\
\hline Explanation & $\begin{array}{l}\text { Why does the blockchain lead to resource reallocation and shifts in competitive power? (i.e. how do the characteristics of the blockchain } \\
\text { change companies' core competencies?) } \\
\text { How does the blockchain impact companies' competitive power? } \\
\text { Under which conditions are blockchain-induced changes especially profound for the SC? (i.e. which industries/strategies/structures are } \\
\text { especially affected?) }\end{array}$ \\
\hline Prediction & Will the blockchain impact the sources of competitive advantage across industries? How will intermediaries of all kinds be affected? \\
\hline $\begin{array}{l}\text { Design and } \\
\text { Action }\end{array}$ & How can one create blockchain solutions that reallocate resources and create new areas of competitive advantage? \\
\hline
\end{tabular}

removed. Then again, a new company $\mathrm{E}$ enters the market and serves as an intermediary between $\mathrm{A}$ and $\mathrm{B}$, which also have a direct relationship.

Figure 4 depicts just some of the changes that can be induced by the blockchain in complex networks of interorganizational relationships. It is again the transparency and non-repudiability of the data which might render personal contacts for enhancing trust obsolete. This is not to say that interorganizational relationships become unnecessary in general, but their overall importance and qualities might change as they are no longer needed to ensure trust in SCs (Werbach, 2018). Similarly, the automated "behavior" of smart contracts makes the execution of business processes predictable. Blockchain technology therefore has the potential to significantly alter the importance of interorganizational relationships and to enable trusted information flows between hitherto disconnected companies, which in turn poses new challenges for management.

In Table VII exemplary research questions are listed that explore the impact of the blockchain from a NT perspective. Again, these questions refine NT such that middle-range theorizing becomes possible.

\section{Discussion}

The blockchain and its potential business implications is a topic that remains under-researched. It was not until the industry had already invested billions of dollars that many applied academic communities, including the logistics/SCM community, realized the need for rigorous research in this area (Treiblmaier and Beck, 2018). One of the major strengths of academia is its capability to provide an unbiased and structured theoretical foundation that can help to guide future research (Simangunsong et al., 2012; Skipper et al., 2008; Svensson, 2002). In this paper, we closely follow an approach previously suggested by Halldórsson et al. (2007) that builds on new institutional economics (Coase, 1937; Williamson, 1987) to provide guidelines on how to structure and manage supply chains. That paper was favorably received by the academic community and thus provides an ideal foundation for investigating the blockchain as a technological artifact that has the potential to significantly disrupt supply chains in various industries. SC managers will face blockchain-induced changes related to the structure, strategy and processes of their companies, as well as to their interrelationships (Strebinger and Treiblmaier, 2006; Treiblmaier and Strebinger, 2008). By 
Figure 4 Traditional NT (left) and blockchain-induced transformations (right)

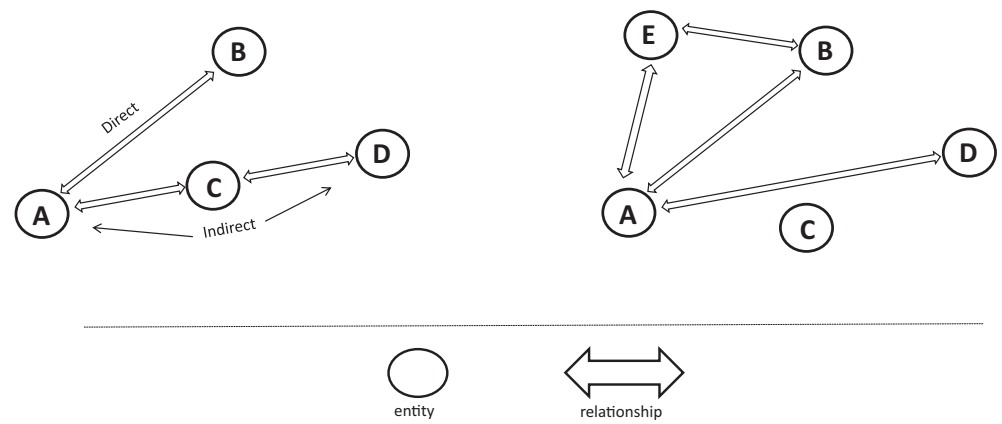

Table VII NT and blockchain: exemplary research questions

\begin{tabular}{|c|c|}
\hline Theory type & Question \\
\hline Analysis & What are the implications of the blockchain for the nature and quality of business relationships? \\
\hline \multirow{3}{*}{ Explanation } & Why does the blockchain change the nature and quality of business relationships? \\
\hline & How does the nature and quality of business relationships change because of increased transparency of information and trust? \\
\hline & $\begin{array}{l}\text { Under which conditions do changes in business relationships have major effects on the } \mathrm{SC} \text { ? (e.g. lower switching barriers for customers } \\
\text { within a value network). }\end{array}$ \\
\hline Prediction & Will the blockchain fundamentally alter the nature and quality of business relationships? \\
\hline $\begin{array}{l}\text { Design and } \\
\text { Action }\end{array}$ & $\begin{array}{l}\text { How can one create blockchain solutions that guarantee contractual performance without requiring established business relationships } \\
\text { within SCs? }\end{array}$ \\
\hline
\end{tabular}

applying the framework presented in this paper, as exemplified by the research questions in Tables IV-VII, valuable insights can be gained as to how the blockchain impacts structural and managerial aspects of the supply chain (Koufteros et al., 2014; McGinnis et al., 2010; Knemeyer and Fawcett, 2015).

\section{Implications}

This research bears significant implications for managers and researchers alike. A recent report from the Gartner group states that "Blockchain technologies are extremely hyped [...] but should not be ignored" (Furlonger et al., 2017). We argue that a methodologically sound and academically rigorous research agenda can benefit both researchers and practitioners. The goals of this paper include defining blockchain and describing its functionality as well as the construction of a framework which supports practitioners and researchers in identifying relevant research questions and exploring the potential implications of blockchain from different theoretical angles.

In this paper, four general theories are presented that can be used to investigate organizational structures, processes and resources, as well as interorganizational relationships from various angles. PAT and TCA originate from neo-classical economic theory and help to answer questions regarding how to structure SCs. They fall short, however, when it comes to taking into account human behavior, critical resources and dynamic relationships (Halldórsson et al., 2007). These factors can be addressed by including RBV and NT, which help to determine what is needed to manage an organizational structure. Taken together, all four theories represent complementary perspectives on (inter)organizational attributes that allow for a comprehensive and in-depth analysis of ongoing and predicted changes.

\subsection{Theoretical implications}

One of the major goals of any scientific discipline is to create and advance theory. Although original theory building efforts in SCM/logistics are scarce (Touboulic and Walker, 2015), the refinement and adaptation of existing grand theories into so-called middle-range theories bears a huge potential to closely investigate the conditions under which logistics phenomena yield certain outcomes (Stank et al., 2017). This paper presents a starting point in the development of middlerange theories by using four well-established and complementary theories (PAT, TCA, RBV, NT) and applying them to postulated changes induced by the blockchain: a technology that has the potential to restructure many logistics/SCM processes (Hackius and Petersen, 2017). The four theories cover both structural (PAT, TCA) as well as managerial (RBV, NT) aspects and, taken together, provide a comprehensive framework for designing future SCM research. Applying the characteristics of the respective theories to the specifics of the blockchain helps researchers to identify potential research areas (cf. Table I).

Following guidelines from the methodological literature (Gregor, 2006), different types of theories are distinguished according to their respective goals (analysis, explanation, prediction, design and action) and research questions of each theory type are identified for each of the theories, as presented in Tables IV-VII. These questions should guide researchers in the further pursuit of relevant and theory-based research topics. More specifically, each of these questions can serve as a starting point for research projects with the goal of analyzing, explaining, predicting and designing the impact of the blockchain on SCM from a specific theoretical angle. Our suggested framework does not impose any restrictions 
pertaining to methodology and is therefore suitable for researchers with both qualitative and quantitative backgrounds.

Furthermore, basing research questions on existing theory allows for the incremental development of a body of research that makes it easier to replicate and, if needed, to dismiss previous findings. Refining theory in this context not only pertains to investigating (i.e. explaining, exploring or predicting) the blockchain as a research phenomenon but also includes research in the "design and action" category that aims at designing and implementing concrete industry solutions. Incremental academic research in this area is especially desirable, as industry projects are often conducted behind closed doors and gains in experience are rarely shared. Academia can help in this regard, for instance, by highlighting best practices for the industry.

\subsection{Managerial implications}

The major part of the existing literature discussing the blockchain is practitioner-oriented and predicts a huge impact of the technology. This is also reflected in current investment levels and industry expectations (Holden and Moar, 2017). Only a few authors warn against raising unrealistic expectations (Walker, 2017; Coppola, 2016). In spite of the huge total investments by the industry, it is mainly the big companies who are at the forefront of this innovation and many logistics operators, especially small and medium-sized companies, lack knowledge about the blockchain (Kersten et al., 2017). To critically and impartially assess its impact, including its potentials and limitations, a repository of methods, frameworks and models are needed that can provide interesting insights for the industry. Academically sound research results that are based on empirical findings and well-founded reasoning rather than on speculation - will benefit decision makers at all levels including commercial organizations as well as governmental and nongovernmental organizations.

In this respect, the logistics/SCM community can build upon a long tradition of theory-based research by adapting existing theories to problems that are of interest for the industry. The four theories that serve as a starting point in this paper are general theories requiring further refinement to create middlerange theories that lend themselves to validation and testing. In this paper, we show how this can be achieved by deriving theory-based research questions that are also relevant for the industry. Combining PAT, TCA, RBV and NT with four theory types according to their respective goals (i.e. analysis, explanation, prediction, design and action) leads to research questions that can help to better understand the implications of the blockchain, as well as providing indications on what is needed to actively take part in the design process.

When it comes to structural issues, PAT explains how complex inter- and intra-organizational dependencies might vanish because of increased information transparency. This guides companies, for example, in redesigning the structure of existing systems (e.g. the level of (dis)intermediation) and critically assessing the information requirements for a specific SC designs. In the next step, such an assessment can be used to design SCs that are more resilient by applying an optimized level of (de)centralization (Treiblmaier, 2018). From a TCA perspective, the focus is on changes in transaction costs and subsequently, in the structure and size of organizations. By investigating the research questions proposed in this paper managers will better understand how attributes of the blockchain can lead to adjustments in organizational size and the design of contractual agreements. This especially pertains to the impact of smart contracts, which are automatically executed and may severely impact transaction costs (Savelyev, 2017).

If the focus is on managerial issues, $\mathrm{RBV}$ can be used to critically assess the role, importance and growth potential of existing organizational resources. Managers might deduce, for example, that a strategic reorganization and delegation of responsibilities is needed to cope with blockchain-induced changes. Such changes may include positive impacts (e.g. an increase in competitive power because of new payment channels) as well as negative impacts (e.g. new competitors that offer simplified processing of shipping documents and help to track goods) (Kshetri, 2018). Finally, NT provides the underlying rationale for assessing the role and importance of companies' interorganizational networks from a relational perspective. For example, analyzing the interplay between relationships and information transparency might inform managers on whether personal relationships can indeed be substituted by the increased information control offered by the blockchain. Additionally, the ease with which new business relationships can be established might change substantially because of "trustless systems" that enforce contractual compliance without any need for personal relationships (Kiviat, 2015).

Taken together, the logistics/SCM community possesses the tools and the methodological knowledge needed to tackle the research questions derived and presented in this paper in a systematic manner. The results from these studies will benefit managers who seek an unbiased, well-founded and thorough understanding of how blockchain technology is impacting and can further impact their own companies and SC networks.

\section{Conclusions, limitations and further research}

Despite the relative novelty of blockchain technology, the industry is already investing millions of dollars and market research predicts a further increase in the years to come (Markets and Markets, 2016). In this paper, we present four grand theories widely used in SCM/logistics research (PAT, TCA, RBV, NET) and make recommendations on how to integrate blockchain technology. The main attributes of the blockchain are considered from the perspective of the four grand theories to develop theoretical frameworks that present relevant topics and questions for logistics/SCM researchers. These frameworks are subsequently refined into research questions that can be used to create middle-range theories for further empirical testing. This paper therefore lays the foundation for further systematic and theory-based research which should not only help to establish a solid research agenda but also bridge the gap between academia and the industry by pointing out those questions that researchers can tackle to better understand the blockchain and its potential implications on SCM.

Given that this paper focuses on a novel technology whose implications are mostly unexplored, three major limitations arise. First, from a technological standpoint the blockchain is 
constantly being developed and does not represent a single monolithic artifact. It is therefore crucial for future researchers to clearly specify what type of blockchain they specifically investigate. In consideration of this issue, this paper discusses the blockchain in a very broad sense without detailing its idiosyncrasies. Second, the selection of theories proposed in this paper to some extent reflects an arbitrary decision, and it has to be acknowledged that other theories that are not mentioned in the paper might as well provide interesting insights. The selection of theories was based on previous research (Halldórsson et al., 2007) whose relevance for the evaluation of SCM was validated several years later (Halldórsson et al., 2015). Obviously, this does not mean that research in this area has to be, or should be, restricted to the application of these four theories. Rather, new middle-range SCM-specific theories might arise by creatively adapting and modifying the suggested theories as well as others to specific problems. Third, the frameworks presented in the paper emerged as a combination of the respective theories with the attributes of blockchain technology, as identified by the authors based on available literature. While this approach is commonly used in the academic literature, further technological advancements or an extended application of a specific theory might yield additional insights that are currently not included in the framework. Additionally, the process of identifying salient research topics and questions, although triggered and bounded by the idiosyncrasies of the specific theories, may result in slightly different results if conducted by a different research team.

This paper presents the first step in putting together a research agenda that applies rigorous academic SCM/logistics research to the blockchain: a potentially disruptive technology with as yet unclear effects on the SC. Incremental research is needed to be able to better understand, predict and, if needed, design blockchain solutions that benefit the logistics industry. Various methodological approaches, such as generalizable empirical studies, can be used to gain a better understanding and identify the most important problems for the industry. A close cooperation between academics and practitioners will best yield results for mutual benefit in this novel research area.

\section{References}

Alabi, K. (2017), "Digital blockchain networks appear to be following Metcalfe's law", Electronic Commerce Research and Applications, Vol. 24 (July-August), pp. 23-29.

Astbury, B. and Leeuw, F.L. (2010), "Unpacking black boxes: mechanisms and theory building in evaluation", American Fournal of Evaluation, Vol. 31 No. 3, pp. 363-381.

Bahga, A. and Madisetti, V.K. (2016), "Blockchain platform for industrial internet of things", Fournal of Software Engineering and Applications, Vol. 9 No. 10, pp. 533-546.

Bahga, A. and Madisetti, V.K. (2017), Blockchain Applications: A Hands-On Approach, VPT, Berlin.

Barney, J.B. (1991), "Firm resources and sustained competitive advantage", Fournal of Management, Vol. 17 No. 1, pp. 99-120.

Carnovale, S. and Yeniyurt, S. (2014), "The role of ego networks in manufacturing joint venture formations", Fournal of Supply Chain Management, Vol. 50 No. 2, pp. 1-17.
Coase, R.H. (1937), "The nature of the firm", Economica, Vol. 4 No. 16, pp. 386-405.

Cocco, L., Pinna, A. and Marchesi, M. (2017), "Banking on Blockchain: costs savings thanks to the Blockchain technology", Future Internet, Vol. 9 No. 3, pp. 1-20.

Coppola, F. (2016), "Blockchain is not going to change the world", Forbes.com, available at: www.forbes.com/sites/ francescoppola/2016/06/13/blockchain-meh/\#2548ce8735ef (accessed 2 October 2017).

Craighead, C.W., Ketchen, D.J. and Cheng, L. (2016), "Goldilocks' theorizing in supply chain research: balancing scientific and practical utility via Middle-Range Theory", Transportation fournal, Vol. 55 No. 3, pp. 241-257.

Defee, C.C., Williams, B., Randall, W.S. and Thomas, R. (2010), "An inventory of theory in logistics and SCM research", The International fournal of Logistics Management, Vol. 21 No. 3, pp. 404-489.

Deloitte (2016), Blockchain: Enigma. Paradox. Opportunity, Deloitte LLP, United Kingdom.

Dresner, M., Yao, Y. and Palmer, J. (2001), "Internet technology use across the food industry supply chain", Transportation fournal, Vol. 40 No. 4, pp. 14-26.

Fayezi, S., O'Loughlin, A. and Zutshi, A. (2012), “Agency theory and supply chain management: a structured literature review", Supply Chain Management: An International fournal, Vol. 17 No. 5, pp. 556-570.

Field, A.M. (2017), "Blockchain for freight?", fournal of Commerce, Vol. 18 No. 5, pp. 88-92.

Furlonger, D., Valdes, R. and Kandaswamy, R. (2017), "Hype cycle for Blockchain technologies 2017”, Gartner Report, available at: www.gartner.com/doc/3775165/hype-cycleblockchain-technologies- (accessed 2 October 2017).

Georgi, C., Darkow, I.-L. and Kotzab, H. (2010), "The intellectual foundation of the journal of business logistics and its evolution between 1978 and 2007", fournal of Business Logistics, Vol. 31 No. 2, pp. 63-109.

Golicic, S.L., Fugate, B.S. and Davis, D.F. (2012), "Examining market information and Brand equity through Resource-Advantage theory: a carrier perspective", fournal of Business Logistics, Vol. 33 No. 1, pp. 20-33.

Google Trends (2018), "Search term: Blockchain", available at: https://trends.google.us/trends/explore?q=blockchain (accessed 18 July 2018).

Grayson, K. and Rust, R. (2001), "Interrater reliability", Fournal of Consumer Psychology, Vol. 20 Nos 1/2, pp. 71-73.

Gregor, S. (2006), "The nature of theory in information systems", MIS Quarterly, Vol. 30 No. 3, pp. 611-642.

Grover, V. and Malhotra, M.K. (2003), "Transaction cost framework in operations and supply chain management research: theory and measurement", fournal of Operations Management, Vol. 21 No. 4, pp. 457-473.

Hackius, N. and Petersen, M. (2017), "Blockchain in logistics and supply chain: trick or treat?", Hamburg International Conference of Logistics, HICL2017, Hamburg

Halldórsson, A., Hsuan, J. and Kotzab, H. (2015), "Complementary theories to supply chain management revisited - from borrowing theories to theorizing", Supply Chain Management: An International fournal, Vol. 20 No. 6, pp. 574-586. 
Halldórsson, A., Kotzab, H., Mikkola, J.H. and Skjøtt-Larsen, T. (2007), "Complementary theories to supply chain management", Supply Chain Management: An International fournal, Vol. 12 No. 4, pp. 284-296.

Harwood-Jones, M. (2016), "Blockchain and T2S: a potential disruptor", Standard Chartered Bank, available at: www.sc. com/BeyondBorders/wp-content/uploads/2016/06/2016-0616-BeyondBorders-Report-SCB_Nema_Block-Chain-PaperFinal.pdf (accessed 2 October 2017).

Holden, W. and Moar, J. (2017), Blockchain Enterprise Survey: Deployments, Benefits \& Attitudes, Juniper Research, Hampshire.

Hunt, S.D. and Davis, D.F. (2008), "Grounding supply chain management in Resource-Advantage theory", The fournal of Supply Chain Management, Vol. 44 No. 1, pp. 10-21.

Huo, B., Han, Z. and Prajogo, D. (2016), "Antecedents and consequences of supply chain information integration: a resource-based view", Supply Chain Management: An International fournal, Vol. 21 No. 6, pp. 661-677.

Iansiti, M. and Lakhani, K.R. (2017), "The truth about Blockchain", Harvard Business Review, Vol. 95 No. 1, pp. 118-127.

IBM (2017), Forward Together: Global C-Suite Study, (19th ed.), IBM Institute for Business Value, IBM Corporation, Armonk, New York, NY.

ISDA (2017), "Smart contracts and distributed ledger - a legal perspective", ISDA Whitepaper, www2.isda.org/attachment/ OTU3MQ==/Smart $\% 20$ Contracts $\% 20$ and $\% 20$ Distributed \%20Ledger $\% 20 \% 20$ A $\% 20$ Legal\%20Perspective.pdf (accessed 22 September 2017).

Jensen, M.C. and Meckling, W.H. (1976), "Theory of the firm: managerial behavior, agency costs and ownership structure", Fournal of Financial Economics, Vol. 3 No. 4, pp. 305-360.

JOC (2017), "Maersk and IBM team up to digitalize supply chain”, fournal of Commerce, Vol. 18 No. 6, pp. 7-8.

Johanson, J. and Mattsson, L.-G. (1987), "Interorganizational relations in industrial systems: a network approach compared with the Transaction-Cost approach", Inter-Organizational Studies of Management and Organization, Vol. 17 No. 1, pp. 34-48.

Kaal, W.A. (2017), "Blockchain solutions for agency problems in corporate governance", 1st Annual Toronto FinTech Conference, 20-21 October, Toronto.

Kambil, A. (1995), "Electronic commerce: implications of the internet for business practice and strategy", Business Economics, Vol. 30 No. 4, pp. 27-33.

Kembro, J., Selviaridis, K. and Näslund, D. (2014), "Theoretical perspectives on information sharing in supply chains: a systematic literature review and conceptual framework", Supply Chain Management: An International Fournal, Vol. 19 Nos 5/6, pp. 609-625.

Kersten, W., Seiter, M., von, See, B., Hackius, N. and Maurer, T. (2017), Trends and Strategies in Logistics and Supply Chain Management - Digital Transformation Opportunities, DVV Media Group, Hamburg.

Kim, S.K., Stump, R.L. and Oh, C. (2009), "Driving forces of coordination costs in Distributor-Supplier relationships: toward a Middle-Range Theory", fournal of the Academy of Marketing Science, Vol. 37 No. 4, pp. 384-399.
Kiviat, T.I. (2015), "Beyond Bitcoin: issues in regulating Blockchain transactions", Duke Law fournal, Vol. 65 No. 3, pp. 569-608.

Klint, M.B. and Sjöberg, U. (2003), "Towards a comprehensive SCP-Model for analysing strategic networks/ alliances", International fournal of Physical Distribution \& Logistics Management, Vol. 33 No. 5, pp. 408 -426.

Knemeyer, A.M. and Fawcett, S.E. (2015), "Supply chain design and integration: why complex collaborative systems are easy to talk about but hard to do", Fournal of Business Logistics, Vol. 36 No. 3, pp. 301-302.

Koufteros, X., Peng, X., Guanyi, L. and Peters, R. (2014), "The impact of organizational structure on internal and external integration", fournal of Organization Design, Vol. 3 No. 2, pp. 1-17.

Kros, J.F. and Nadler, S.S. (2010), "The impact of SarbanesOxley on off-Balance Sheet supply chain activities", fournal of Business Logistics, Vol. 31 No. 1, pp. 63-77.

Kshetri, N. (2018), "Blockchain's roles in meeting key supply chain management objectives", International fournal of Information Management, Vol. 39 (April), pp. 80-89.

Kulmala, H.I. and Uusi-Rauva, E. (2005), "Network as a business environment: experiences from software industry", Supply Chain Management: An International fournal, Vol. 10 No. 3, pp. 169-178.

Lancioni, R., Schau, H.J. and Smith, M.F. (2003), "Internet impacts on supply chain management", Industrial Marketing Management, Vol. 32 No. 3, pp. 173-175.

Liang, X., Shetty, S., Tosh, D., Kamhoua, C., Kwiat, K. and Njilla, L. (2017), "Provchain: a Blockchain-Based data provenance architecture in cloud environment with enhanced privacy and availability", Proceedings of the 17th IEEE/ACM International Symposium on Cluster, Cloud and Grid Computing, Madrid, Spain, 468-477.

Luzzini, D., Caniato, F., Ronchi, S. and Spina, G. (2012), "A transaction costs approach to purchasing portfolio management", International fournal of Operations \& Production Management, Vol. 32 No. 9, pp. 1015-1042.

MacInnis, D.J. (2011), “A framework for conceptual contributions in marketing”, fournal of Marketing, Vol. 75 No. 4, pp. 136-154.

Madhok, A. (2002), "Reassessing the fundamentals and beyond: ronald coase, the transaction cost and resourcebased theories of the firm and the institutional structure of production", Strategic Management Fournal, Vol. 23 No. 6, pp. 535-550.

Manuj, I., Omar, A. and Yazdanparast, A. (2013), "The quest for competitive advantage in global supply chains: the role of interorganizational learning", Transportation fournal, Vol. 52 No. 4, pp. 463-492.

MarEx (2017), "Blockchain currency ready for container shipping", The Maritime Executive, http://maritimeexecutive.com/article/blockchain-currency-ready-for-containershipping (accessed 7 September 2017).

Markets and Markets (2016), Blockchain Market by Provider, Application (Payments, Exchanges, Smart Contracts, Documentation, Digital Identity, Clearing and Settlement), Organization Size, Vertical, and Region - Global Forecast to 2021, Market Report, MarketsandMarkets.com. 
McGinnis, M.A., Kohn, J.W. and Spillan, J.E. (2010), “A longitudinal study of logistics strategy: 1990-2008”, fournal of Business Logistics, Vol. 31 No. 1, pp. 217-235.

Miemczyk, J., Howard, M. and Johnsen, T.E. (2016), "Dynamic development and execution of Closed-Loop supply chains: a natural Resource-Based view", Supply Chain Management: An International fournal, Vol. 21 No. 4, pp. 453-469.

Miller, J.W., Saldanha, J.P., Hunt, C.S. and Mello, J.E. (2013), "Combining formal controls to improve firm performance", Fournal of Business Logistics, Vol. 34 No. 4, pp. 301-318.

Morabito, V. (2017), Business Innovation through Blockchain: The B3 Perspective, Springer, Cham.

Nakamoto, S. (2008), "Bitcoin: a peer-to-Peer Electronic cash system", available at: https://bitcoin.org/en/bitcoin-paper (accessed 12 August 2017).

Narayanan, V.G., Raman, A. and Singh, J. (2005), “Agency costs in a supply chain with demand uncertainty and price competition", Management Science, Vol. 51 No. 1, pp. 120-132.

Narayanan, A., Bonneau, J., Felten, E., Miller, A. and Goldfeder, S. (2016), "Bitcoin and cryptocurrency technologies: a comprehensive introduction", Princeton University Press, Princeton.

Neisse, R., Steri, G. and Nai-Fovino, I. (2017), “A BlockchainBased approach for data accountability and provenance tracking", Proceedings of the 12th International Conference on Availability, Reliability and Security, Reggio Calabria, Italy, Article No. 14, pp. 1-9.

Oakley, T. (2017), "Zillerium: a decentralised supply chain management architecture", White Paper, available at: www. zillerium.com/draftwhitepaperupi.pdf (accessed 22 September 2017).

Ogundeji, O. (2016), "Blockchain can disrupt the disruptors in Uber and Airbnb", Cryptocoin News, available at: www. cryptocoinsnews.com/blockchain-can-disrupt-the-disruptorsin-uber-and-airbnb/ (accessed 2 October 2017).

Picot, A., Bortenlanger, C. and Rohrl, H. (1997), "Organization of electronic markets: contributions from new institutional economics”, Information Society, Vol. 13 No. 1, pp. 107-123.

Porter, M. (1980), Competitive Strategy: Techniques for Analyzing Industries and Competitors, Free Press, New York, NY.

Raval, S. (2016), Decentralized Applications: Harnessing Bitcoin's Blockchain Technology, O'Reilly, Beijing, Boston, Farnham, Sebastopol, Tokyo.

Rinehart, L.M., Eckert, J.A., Handfield, R.B., Page, T.J. and Atkin, T. (2004), "An assessment of Supplier-Customer relationships", fournal of Business Logistics, Vol. 25 No. 1, pp. 25-62.

Romano, D. and Schmid, G. (2017), "Beyond Bitcoin: a critical look at Blockchain-Based systems", Cryptography, Vol. 1 No. 2, available at: www.mdpi.com/2410-387X/1/2/ 15/htm (accessed 26 September 2017).

Savelyev, A. (2017), “Contract law 2.0: 'smart' contracts as the beginning of the end of classic contract law", Information $\mathcal{E}$ Communications Technology Law, Vol. 26 No. 2, pp. 116-134.
Simangunsong, E., Hendry, L.C. and Stevenson, M. (2012), "Supply-Chain uncertainty: a review and theoretical foundation for future research", International fournal of Production Research, Vol. 50 No. 16, pp. 4493-4523.

Skipper, J.B., Craighead, C.W., Byrd, T.A. and Rainer, R. K. (2008), "Towards a theoretical foundation of supply network interdependence and Technology-Enabled coordination strategies", International fournal of Physical Distribution \& Logistics Management, Vol. 38 No. 1, pp. 39-56.

Skjoett-Larsen, T. (1999), "Supply chain management: a new challenge for researchers and managers in logistics", The International fournal of Logistics Management, Vol. 10 No. 2, pp. 41-53.

Stank, T.P., Pellathy, D.A., In, J., Mollenkopf, D.A. and Bell, J.E. (2017), "New frontiers in logistics research: theorizing at the Middle range", Fournal of Business Logistics, Vol. 38 No. 1, pp. 6-17.

Stock, J.R. (1997), "Applying theories from other disciplines to logistics", International fournal of Physical Distribution $\mathcal{G}$ Logistics Management, Vol. 27 Nos 9/10, pp. 515-539.

Stranieri, S., Orsi, L. and Banterle, A. (2017), "Traceability and risks: an extended transaction cost perspective", Supply Chain Management: An International fournal, Vol. 22 No. 2, pp. 145-159.

Strebinger, A. and Treiblmaier, H. (2006), "The impact of business to consumer E-Commerce on organizational structure, Brand architecture, IT structure and their interrelations", Schmalenbach Business Review, Vol. 58 No. 1, pp. 81-113.

Svensson, G. (2002), "The theoretical foundation of supply chain management", International fournal of Physical Distribution \& Logistics Management, Vol. 32 No. 9, pp. 734-754.

Swanson, D., Goel, L., Francisco, K. and Stock, J. (2017), "Applying theories from other disciplines to logistics and supply chain management: a systematic literature review", Transportation fournal, Vol. 56 No. 3, pp. 299-356.

Tapscott, D. and Tapscott, A. (2016), Blockchain Revolution: How the Technology behind Bitcoin is Changing Money, Business, and the World, Penguin, New York, NY.

Tate, W.L., Dooley, K.J. and Ellram, L.M. (2011), "Transaction cost and institutional drivers of supplier adoption of environmental practices”, fournal of Business Logistics, Vol. 32 No. 1, pp. 6-16.

Touboulic, A. and Walker, H. (2015), "Theories in sustainable supply chain management: a structured literature review", International fournal of Physical Distribution \& Logistics Management, Vol. 45 Nos 1/2, pp. 16-42.

Treiblmaier, H. (2018), "Optimal levels of (De)centralization for resilient supply chains", The International fournal of Logistics Management, Vol. 29 No. 1, pp. 435-455.

Treiblmaier, H. and Beck, R. (2018), Business Transformation through Blockchain, Volumes I+II, Palgrave Macmillan, Basingstoke, England.

Treiblmaier, H. and Strebinger, A. (2008), "The effect of ECommerce on the integration of IT structure and Brand architecture", Information Systems fournal, Vol. 18 No. 5, pp. 479-498. 
Tschorsch, F. and Scheuermann, B. (2016), "Bitcoin and beyond: a technical survey on decentralized digital currencies”, IEEE Communications Surveys \& Tutorials, Vol. 18 No. 3, pp. 2084-2123.

UK Government (2016), Distributed Ledger Technology: Beyond Block Chain, Report by the UK Government Chief Scientific Advisor, Government Office for Science, London.

Wacker, J.G., Yang, C. and Sheu, C. (2016), "A transaction cost economics model for estimating performance effectiveness of relational and contractual governance: theory and statistical results", International fournal of Operations $\mathcal{E}$ Production Management, Vol. 36 No. 11, pp. 1551-1575.

Walker, M. (2017), "Seven signs of over-Hyped Fintech", LSE Business Review, Blog Entry, London School of Economics and Political Science, available at: http://blogs.lse.ac.uk/ businessreview/2017/07/04/seven-signs-of-over-hyped-fintech/ (accessed 26 September 2017).

Werbach, K. (2018), "Trust, but verify: why the Blockchain needs the law", Berkeley Technology Law fournal, available at: www.techpolicy.com/Articles/T/Trust,-But-Verify-Why-theBlockchain-Needs-the-La.aspx

Wernerfelt, B. (1984), "A Resource-based view of the firm", Strategic Management fournal, Vol. 5 No. 2, pp. 171-180.

Whipple, J.M. and Roh, J. (2010), “Agency theory and quality fade in buyer-supplier relationships", The International Fournal of Logistics Management, Vol. 21 No. 3, pp. 338-352.

Wichmann, B.K., Carter, C.R. and Kaufmann, L. (2015), "How to become Central in an informal social network: an investigation of the antecedents to network centrality in an environmental SCM initiative", Fournal of Business Logistics, Vol. 36 No. 1, pp. 102-119.
Williamson, O.E. (1987), "Transaction cost economics: the comparative contracting perspective", Fournal of Economic Behavior E Organization, Vol. 8 No. 4, pp. 617-625.

World Economic Forum (2017), "Realizing the Potential of Blockchain: A Multistakeholder Approach to the Stewardship of Blockchain and Cryptocurrencies", White Paper WEF, World Economic Forum, Geneva, Switzerland.

Yang, C.-S. and Lirn, T.-C. (2017), "Revisiting the ResourceBased view on logistics performance in the shipping industry", International fournal of Physical Distribution \& Logistics Management, Vol. 47 No. 9, pp. 884-905.

Yao, Y., Dresner, M. and Palmer, J.W. (2009), "Impact of Boundary-Spanning information technology and position in chain on firm performance", fournal of Supply Chain Management, Vol. 45 No. 4, pp. 3-16.

Yigitbasioglu, O.M. (2010), "Information sharing with key suppliers: a transaction cost theory perspective", International fournal of Physical Distribution \& Logistics Management, Vol. 40 No. 7, pp. 550-578.

Zsidisin, G.A. and Ellram, L.M. (2003), "An agency theory investigation of supply risk management", The fournal of Supply Chain Management, Vol. 39 No. 3, pp. 15-27.

$\mathrm{Zu}, \mathrm{X}$. and Kaynak, H. (2012), "An agency theory perspective on supply chain quality management", International fournal of Operations \& Production Management, Vol. 32 No. 4, pp. 423-446.

\section{Corresponding author}

Horst Treiblmaier can be contacted at: horst.treiblmaier@ modul.ac.at 